\title{
Immunological Reactivity in Patients with Carcinoma of Colon
}

\author{
R. C. NAIRN, A. P. P. NIND, \\ E. P. G. GULI, \\ D. J. DAVIES, J. M. ROLLAND, \\ A. R. McGIVEN, \\ E. S. R. HUGHES \\ [With Special Plate]
}

plasm-reactive serum antibodies. The only differences were that special attention was paid to (a) removing mucus from the original tumour cell suspension by additional washing in

\section{Summary}

Sixty cases of colonic carcinoma have been investigated for antitumour immunoreactivity. The tests employed were blood lymphocyte reactivity and complementdependent serum cytotoxicity against cultured tumour cells, and immunofluorescence for membrane staining of viable tumour cells and cytoplasmic staining of dried tumour cells in films. Nineteen cases were positive by one or more tests and the most frequent positive response, lymphocytotoxicity, was detected in 8 of the 24 cases tested in this way. The lymphocytotoxicity persisted in a case tested three times over a year. Immunoreactivity against tumour cell surface, as by lymphocyte or serum cytotoxicity or membrane immunofluorescence, was restricted to colonic carcinomas but there was an additional element of individual specificity; cross-reactivity with other tissues and tumours was not observed. Lymphocytes from regional lymph nodes were non-reactive even in a case with positive blood lymphocyte cytotoxicity against the carcinoma cells.

\section{Introduction}

Colonic carcinoma has been a favoured target of immunologists for a decade. Interest in deletion of intestine-specific antigens from the carcinomas (Nairn et al., 1962) was followed by the detection of re-emergent embryonic antigens in them (Gold and Freedman, 1965), of circulating antibodies to these antigens (Gold, 1967), and of cellular immunity, possibly against similar targets (Hellström et al., 1970). So far there has not been a general survey of antitumour reactivity by diverse tests in a large series of patients. In the present investigation of 60 cases of colonic carcinoma antitumour activity by patients' sera and peripheral blood lymphocytes was studied by the same immunofluorescence and cultural serum and lymphocyte cytotoxicity tests as for human skin carcinoma (Nairn et al., 1971). Immunoreactivity by one or more of the tests was found in more than $30 \%$ of all patients investigated and in more than $50 \%$ of those examined by every test.

\section{Methods}

The following procedures were virtually identical with those already described for skin carcinomas (Nairn et al., 1971): tumour and blood sample collection; preparation of tumour cell and lymphocyte suspensions; culture and any freezestorage of cells; and tests on tumour cells for lymphocytotoxicity, complement-dependent serum cytotoxicity in culture, and, by immunofluorescence, for membrane-reactive and cyto-

\footnotetext{
Department of Pathology, Monash University Medical School, Melbourne

R. C. NAIRN, M.D., PH.D., Professor

A. P. P. NIND, B.SC., Research Assistant

E. P. G. GULI, M.D., DIP.ONC., Associate Professor

D. J. DAVIES, M.D., B.SC., Senior Lecturer

J. M. ROLLAND, B.SC., PH.D., Senior Teaching Fellow

A. R. McGIVEN, M.D., PH.D., Associate Professor

Royal Melbourne Hospital, Melbourne

E. S. R. HUGHES, M.S., F.R.A.C.S., Surgeon
} medium 199 and filtering through layers of cotton gauze, and (b) avoiding overgrowth of microbial contaminants in culture by adding extra antibiotics. Benzylpenicillin (500 IU/ml), ampicillin $(125 \mu \mathrm{g} / \mathrm{ml})$, streptomycin sulphate $(125 \mu \mathrm{g} / \mathrm{ml})$, and nystatin $(100 \mathrm{IU} / \mathrm{ml})$ were used routinely. Despite the abundance of micro-organisms in the original tumour cell suspensions the initial washing and the antibiotic mixture permitted successful growth in more than three-quarters of the cultures, apparently uninfluenced by contamination. Nevertheless, the tests on the cell suspensions were more frequently troublesome than with non-mucinous, less-contaminated tumours. Special care was required in immunofluorescence tests in the correct interpretation of any stained mucinous debris or microorganisms either free or attached to tumour cells. Triplicating cytotoxicity tests was particularly important because sporadic cultures throughout a test series become useless from overgrowth of micro-organisms.

The cell suspensions in general contained not less than $80 \%$ tumour cells with dye exclusion viability from 1 to $90 \%$, most commonly around $15 \%$. Though the dye exclusion test usually gave a fair indication of the potential for tumour cell growth in culture it often did not correlate well at low values, and tumours even with $1 \%$ viability sometimes grew adequately for satisfactory cytotoxicity tests. The tumour cells were readily identified from their columnar shape and granular cytoplasm (Special Plate, Fig. 1).

In the absence of serum cytotoxicity or lymphocytotoxicity carcinoma cells usually grew well on the coverglass of the culture chambers (Special Plate, Fig. 2), free of dead cells and debris, which fell away from the upper viable monolayer. It should be recalled that it is the formation of this monolayer of readily identifiable tumour cells which indicates absence of cytotoxicity. Any cytotoxic effect will be exerted either from the outset on tumour cells in suspension, preventing their attachment to glass, or subsequently on some which initially succeed in growing on glass. When these are damaged by serum or lymphocyte toxicity they round up, show other evidence of degeneration, and fall away from the coverglass. A positive response is thus indicated by the presence of very few, mainly degenerate carcinoma cells on the coverglass by the fifth day of culture, as opposed to proliferation of a monolayer of carcinoma cells in parallel control experiments.

In lymphocytotoxic reactions tumour cells have one or more lymphocytes firmly attached to them (Special Plate, Fig. 3) that cannot be dislodged, as in the case of cells in casual contact, by tapping the coverglass during microscopical observation. The ratio of added lymphocytes to tumour cells whether viable or non-viable has been about $2 \cdot 5: 1$ at the start of culture. The non-viable cells might well have surface antigenic deficiency, so that the lymphocyte to viable tumour cell ratio could be the important criterion to consider. This, however, can only be numerically assessed when the culture is first set up in terms of some arbitrary cell viability test, which may not infrequently fail to reflect tumour growth potential. All that can be said is that the number of added lymphocytes per viable tumour cell varied from culture to culture between the extremes of about 3 and 250. Our experimental data have not revealed that variability in this proportion or in tumour growth potential has influenced actual lymphocytotoxicity results. 
Time-lapse cinephotomicrography was employed to examine in detail one positive lymphocytotoxicity culture, as already described for squamous cell carcinoma. The lymphocytes were added to a five-day tumour culture giving a final ratio of 10 to 1 tumour cell while at the same time replacing the original with fresh medium. Cine-film was obtained of initial lymphocyte contact and attachment to a tumour cell.

In four cases lymphocytes for toxicity testing against the tumour cells were obtained from regional lymph nodes received with the carcinoma specimens.

By membrane immunofluorescence positive viable cells in suspension showed the characteristic speckled surface staining and also occasional aggregation at one pole of the cell, possibly reflecting concentration of antigenic material at the luminal border (Special Plate, Figs. 4 and 5). Cytoplasmic immunofluorescence on dried cell films sometimes showed polar or bipolar distribution of staining (Special Plate, Fig. 6). By either immunofluorescence test extreme care and "blind" recording by an experienced fluorescence microscopist have been essential to obtain consistently reliable results. In negative control tests there should be virtually no staining of intact tumour cells, and in positive tests the majority of identifiable tumour cells should be unequivocally stained. Minor populations of non-tumour cells, fragments, mucous debris, and microorganisms may stain nonspecifically in both test and control preparations; they must be distinguished morphologically and ignored in assessment of the antitumour reactivity.

\section{IMMUNOLOGICAL SPECIFICITY}

Tests of specificity were the same as in the squamous cell carcinoma study but on a much larger series of cases. Lymphocyte and serum reactivity were tested against normal colonic mucosal cells from the same or other patients and against different carcinomas of the colon and of other organs. In addition the serum cytotoxicity tests were done with added human blood group AB serum complement before and after inactivation. Serum absorptions for serum cytotoxicity and immunofluorescence studies of the colonic carcinomas were made with autologous and homologous carcinomas of the colon and normal colon and homologous normal liver.

Monospecific antihuman-globulin conjugates were used to examine the immunoglobulin class responsible for any positive immunofluorescent staining. All positive sera were also examined by immunofluorescence for possible autoantibodies against normal colon mucosa, nuclei, mitochondria, smooth muscle, and other normal tissue elements. Antimitochondrial activity may give misleading cytoplasmic immunofluorescence of carcinoma cells but it is of distinct granular pattern (Special Plate, Fig. 7) and can be recognized by its wide cross-reactivity and from the routine autoantibody testing.

\section{Results}

The total of 60 cases studied were selected only in so far as they had carcinomas of the colon resectable at operation as part of normal patient care. Most of the operations (44) were conducted personally by E.S.R.H., the remainder severally by surgical colleagues in hospitals in and around Melbourne. The patients ( 30 men, 30 women) were aged 28 to 89 years. All the tumours were adenocarcinomas without unusual histopathological features. They were graded clinicopathologically as (1) confined to colon, (2) extending only locally, and (3) disseminated.

Complete examination by all four tests was made in only 21 cases; the others had different combinations of tests (Table I). Of the 21 cases examined by all tests 11 showed one or more positive reactions; as expected, less comprehensive testing was associated with a smaller proportion of positive results. Of the 60 cases 19 showed at least one type of reactivity between either their blood lymphocytes or their serum and their own tumour; more than one response was observed in seven cases. The commonest single positive reaction was lymphocytotoxicity,
TABLE I-Different Test Combinations in the 60 Cases of Colonic Carcinoma

\begin{tabular}{|c|c|c|c|c|c|c|}
\hline \multicolumn{2}{|c|}{$\begin{array}{l}\text { Tested for } \\
\text { Cytotoxicity }\end{array}$} & \multicolumn{2}{|c|}{$\begin{array}{c}\text { Tested for } \\
\text { Immunofluorescence }\end{array}$} & \multirow[b]{2}{*}{$\begin{array}{c}\text { Positive } \\
\text { by Any } \\
\text { Test }\end{array}$} & \multirow{2}{*}{$\begin{array}{c}\begin{array}{c}\text { No. of } \\
\text { Cases: }\end{array} \\
\begin{array}{c}\text { Negative } \\
\text { by All } \\
\text { Tests }\end{array}\end{array}$} & \multirow[b]{2}{*}{ Total } \\
\hline$\underset{\text { cyte }}{\text { Lympho- }}$ & Serum & Membrane & Cytoplasm & & & \\
\hline $\begin{array}{l}\text { Yes } \\
\text { Yes } \\
\text { Yes } \\
\text { No } \\
\text { No } \\
\text { No } \\
\text { No }\end{array}$ & $\begin{array}{l}\text { Yes } \\
\text { Yes } \\
\text { No } \\
\text { Yes } \\
\text { No } \\
\text { No } \\
\text { No }\end{array}$ & $\begin{array}{l}\text { Yes } \\
\text { No } \\
\text { Yes } \\
\text { Yes } \\
\text { Yes } \\
\text { Yes } \\
\text { No }\end{array}$ & $\begin{array}{l}\text { Yes } \\
\text { Yes } \\
\text { Yes } \\
\text { Yes } \\
\text { Yes } \\
\text { No } \\
\text { Yes }\end{array}$ & $\begin{array}{r}11 \\
1 \\
1 \\
4 \\
2 \\
0 \\
0\end{array}$ & $\begin{array}{r}10 \\
0 \\
1 \\
12 \\
13 \\
1 \\
4\end{array}$ & $\begin{array}{r}21 \\
1 \\
2 \\
16 \\
15 \\
1 \\
4\end{array}$ \\
\hline
\end{tabular}

None of the other possible test combinations occurred.

which occurred in 8 out of 24 cases tested. Serum cytotoxicity had a lower incidence, 4 out of 38 cases, and all four cases positively reacting also showed lymphocytotoxicity. Membrane immunofluorescence tests were positive in 7 out of 55 cases and cytoplasmic immunofluorescence tests in 10 out of 59. Altogether 16 positive cases were detected by one or more of the three serum tests. Cases 1 to 19 were autologous-positive by at least one test while Cases 20 to 60 were autologous-negative by all tests done. There was no example of globulin binding to the tumour in vivo in any of the patients. The incidence of positive tests is undoubtedly an underestimate because of the frequency with this tumour of incomplete testing for a variety of technical or clinical reasons.

Repeat tests against frozen-stored tumour cells with stored serum gave the same results as originally, with only minor variations in intensity. When the stored cells were retested with fresh samples of autologous serum or lymphocytes obtained up to a year after the original tumour resection the results varied more in that serum reactions were occasionally reversed; there was remarkably consistent positive reactivity over a year by three separate lymphocyte samples from Case 1 (Table II).

Lymphocytes from regional lymph nodes were not cytotoxic for autologous tumour cells in any of the four cases studiedone of these (Case 4) showed blood lymphocyte and serum cytotoxicity, one showed neither, and in the other two blood lymphocytes were not tested, though one (Case 13) was seropositive by immunofluorescence. Any lymphocytes carried over from the tumour tissue in the original cell suspension also appeared to have no cytotoxic effect.

There was nothing in the series to suggest any influence on the results obtained of age, sex, blood group, or anatomical site or histopathological appearance of the tumours. The latter included an assessment of lymphocytic infiltration of the carcinomas, though there is little prospect in this tumour of identifying it as an immunological response to viable tumour, necrotic tissue, or invading bowel organisms. There was no correlation between the immunological results and clinicopathological grading of the tumours except that of the six cases showing positive cytoplasmic immunofluorescence alone, three had obvious metastatic spread soon after operation. No beneficial effect on the immediate fate of the patient by any antitumour immunoreactivity

TABLE II-Reactivity of Repeat Serum and Blood Lymphocyte Samples on Original Autologous Colonic Carcinoma Cells

\begin{tabular}{|c|c|c|c|c|c|}
\hline \multirow{2}{*}{ Case No. } & \multirow{2}{*}{ Date } & \multicolumn{2}{|c|}{ Cytotoxicity } & \multicolumn{2}{|c|}{ Immunofluorescence } \\
\hline & & $\overline{\text { Lymphocyte }}$ & Serum & Membrane & Cytoplasm \\
\hline 1 & $\left\{\begin{array}{c}4 / 7 / 70 \\
16 / 10 / 70 \\
29 / 7 / 71\end{array}\right.$ & $\begin{array}{l}+ \\
+ \\
+\end{array}$ & $\underline{-}$ & $\begin{array}{l}\overline{+} \\
+\end{array}$ & $\overline{-}$ \\
\hline 2 & $\left\{\begin{array}{l}14 / 7 / 71 \\
24 / 9 / 71\end{array}\right.$ & $\ldots$ & \pm & - & $\begin{array}{l}+ \\
+\end{array}$ \\
\hline 3 & $\left\{\begin{array}{r}8 / 10 / 70 \\
17 / 11 / 70\end{array}\right.$ & + & $\overline{-}$ & $\stackrel{+}{+}$ & $\stackrel{+}{+}$ \\
\hline 5 & $\left\{\begin{array}{l}18 / 8 / 71 \\
20 / 9 / 71\end{array}\right.$ & $\dddot{x}$ & \pm & - & - \\
\hline 8 & $\left\{\begin{array}{r}7 / 7 / 71 \\
20 / 9 / 71\end{array}\right.$ & $\dddot{t}$ & - & - & - \\
\hline 26 & $\left\{\begin{array}{l}12 / 5 / 71 \\
13 / 7 / 71\end{array}\right.$ & $\underline{-}$ & $\overline{-}$ & - & - \\
\hline 27 & $\left\{\begin{array}{l}10 / 9 / 71 \\
21 / 9 / 71\end{array}\right.$ & $\underline{-}$ & $\overline{-}$ & - & - \\
\hline
\end{tabular}

Not examined 
could be discerned. The only autoantibody to normal tissues in the 19 immunopositive cases was against gastric parietal cells in Case 15-it had no apparent relevance; the 41 immunonegative cases included two with antigastric parietal cell activity and one with antinuclear factor. Two patients with positive lymphocytotoxicity had the incidental immunological diseases asthma and rheumatoid arthritis.

\section{CROSS-REACTIVITY STUDIES}

Lymphocytes from 15 of the cases, including seven with autologous-positive lymphocytotoxicity, were investigated against one or more of the following targets: other colonic carcinomas, malignant melanomas, squamous cell carcinoma, and normal autologous or homologous colon mucosa. The only crossreactivity observed was in four autologous-positive cases tested against colonic carcinomas; four different target colonic carcinomas (three autologous-positive and one untested) were used in this investigation. The cross-reacting lymphocytotoxicity was always weaker than the original autologous response, suggesting that the latter had a degree of individual specificity. Eight autologous-negative cases did not cross-react with any target. Lymphocytes from 11 cases (including six autologous-positive) tested against non-colonic carcinomas or normal colon mucosa gave negative results.

Serum cytotoxicity was examined for cross-reactivity in four cases. Autologous-positive Case 5 reacted less strongly with a homologous colonic carcinoma and not at all with autologous or homologous normal colon or with a melanoma. Autologousnegative Case 3 was tested against homologous colonic carcinoma and normal colon and did not react. Autologous-positive Cases 2 and 4 tested only against homologous normal colon also did not react. Thus again there is evidence of partial crossreactivity limited to other colonic carcinomas.

Membrane immunofluorescence cross-reactivity tests were made with seven sera against the cells of five colon carcinomas. The results are summarized in Table III, which shows uneven cross-reactivity by both autologous-positive and autologous-

TABLE III-Cross-reactivity by Membrane Immunofluorescence. Sera from Patients with Colonic Carcinoma against Homologous Colonic Carcinoma Cells

\begin{tabular}{|c|c|c|c|c|c|c|c|c|}
\hline \multirow{2}{*}{\multicolumn{3}{|c|}{$\begin{array}{l}\text { Serum from } \\
\text { Case No.: }\end{array}$}} & \multirow{2}{*}{$\begin{array}{c}\begin{array}{c}\text { Blood } \\
\text { Group }\end{array} \\
\text { B }\end{array}$} & \multicolumn{5}{|c|}{ Reaction versus Cells of Case: } \\
\hline & & & & $1 *$ & $3^{*}$ & 7 & $11^{*}$ & 19 \\
\hline $\begin{array}{c}1 \\
3 * \\
4 \dagger \\
7 \dagger \\
79^{*} \\
19 \\
23\end{array}$ & $\begin{array}{l}. \\
\ldots \\
\ldots \\
\ldots \\
\ldots\end{array}$ & $\begin{array}{l}. \\
\therefore \\
\ldots \\
\ldots \\
.\end{array}$ & $\begin{array}{l}\mathbf{B} \\
\mathrm{O} \\
\mathrm{O} \\
\mathbf{A} \\
\mathrm{A} \\
\mathbf{B} \\
\mathbf{A}\end{array}$ & $\begin{array}{l}- \\
+ \\
+ \\
- \\
+ \\
+ \\
+\end{array}$ & $\begin{array}{l}\overline{+} \\
+ \\
+ \\
+ \\
+ \\
+\end{array}$ & $\begin{array}{l}\overline{-} \\
\overline{-} \\
\bar{z} \\
\overline{+} \\
\overline{-}\end{array}$ & $\begin{array}{l}- \\
\overline{+} \\
\dot{-} \\
\overline{+} \\
+\end{array}$ & $\begin{array}{l}\overline{-} \\
\overline{-} \\
+ \\
\overline{-} \\
+\end{array}$ \\
\hline
\end{tabular}

*Autologous membrane immunofluorescence-positive.

+Positivity of autologous membrane immunofluorescence in doubt.

Case 1 serum sample in this test was autologous-negative (cf Table II)

Blood group of Case 11, $\mathrm{O}$.

negative cases, presumably reflecting reactions between plural antibody-antigen systems. There was some suggestion of greater cross-reactivity against autologous-positive cells. Tests with seven autologous-positive sera (Cases 1, 3, 9, 10, 11, 12, and 13) against two different samples of homologous normal colonic mucosal cells (Case 5 and one other) were negative. Two of the sera (Cases 3 and 10) were also negative against the cells of a squamous cell carcinoma and of a melanoma. The findings showed no correlation with the patients' blood groups.

Cytoplasmic immunofluorescence (Table IV) showed similar diversity of cross-reactivity but with commoner positive reactions by the autologous-positive sera. There was no consistent correspondence with the membrane immunofluorescence results. Again there is a suggestion of multiplicity of antibodies and antigens, but they are apparently different from those detected by the membrane staining. The reactions did not correlate with blood groups. The same two samples of normal colonic mucosa and of skin tumours as tested by membrane immunofluorescence
TABLE IV-Cross-reactivity by Cytoplasmic Immunofluorescence

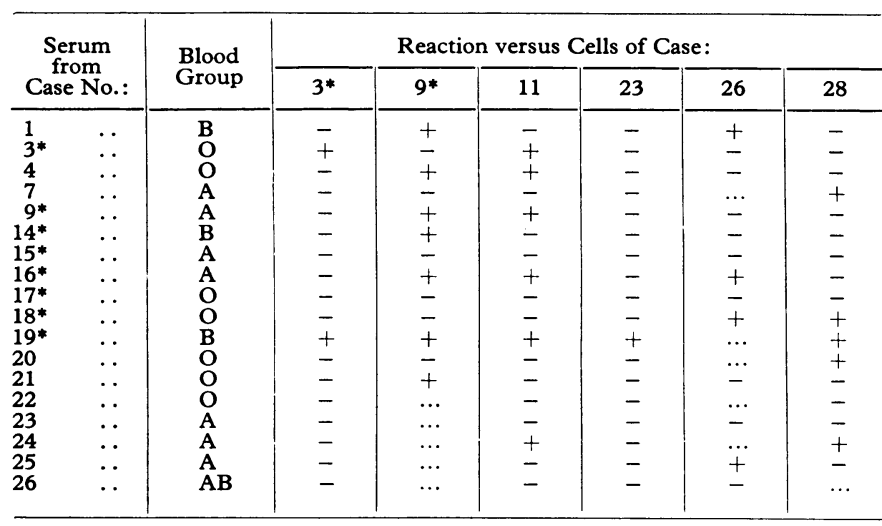

*Autologous cytoplasmic immunofluorescence positive. Blood group of Case 11, O; Case 28, B.

were examined for cytoplasmic reactivity with the same sera, again with negative results.

One autologous-positive serum (Case 19) showed unusually consistent cross-reactivity against all colonic carcinomas tested. It also cross-reacted similarly by membrane immunofluorescence, as already indicated in Table III, though itself autologous-negative by this test. Furthermore, this serum crossreacted by cytoplasmic immunofluorescence with mucosal cell samples of two homologous normal colons. The breadth of this cross-reactivity was not fully explored but it persisted after absorption of the serum with human group $\mathrm{AB}$ erythrocytes. No generally recognized autoantibody against normal tissues was detected in the serum; in particular there was none against sections of normal colonic mucosa, as may occur in ulcerative colitis.

Serum absorptions provided complementary data on crossreactivity both in cytotoxicity and immunofluorescence tests. A serum positive by three of four tests (Case 1) showed no significant diminution of cytotoxicity against autologous tumour cells after serum absorption by autologous or homologous colon mucosa or by homologous liver. Autologous tumour neutralized the serum completely and a colonic carcinoma from another patient was almost as effective. These findings gave a clear indication of tumour specificity and again a suggestion of individual specificity. This was supported by the results in immunofluorescence tests on an autologous-positive serum (Case 13). Here membrane immunofluorescence was prevented completely by serum absorption with autologous colonic carcinoma but only partially with autologous normal colon and not at all with homologous colonic carcinoma, normal colon, or liver. Cytoplasmic immunofluorescence was studied with serum absorptions in five cases, not always conclusively for technical reasons, but there was undoubted wider crossreactivity than other tests have shown. Neutralization of sera by absorption was most efficient with colonic carcinomas whether autologous or homologous; normal colon, and in one case liver, were almost as effective.

\section{OTHER CONTROL OBSERVATIONS}

Lymphocytes from 15 subjects without colonic carcinoma showed no reactivity against cultures of 22 of the colonic carcinomas, including cases autologous-positive by any test $(1,2,3,4,5,6,7$, $8,11,12,15$, and 19). The lymphocyte donors comprised four patients with malignant melanoma, three with squamous cell carcinoma, four with other carcinomas, one with a benign colonic polyp, and three normal subjects.

Sera from many subjects either normal or with carcinomas other than of the colon were employed as controls in cytotoxicity and immunofluorescence tests; none ever gave a positive result. No example of serum cytotoxicity was observed in the absence of active human complement. Study of the immunoglobulin class 
in five sera (Cases 1, 3, 11, 13, and 19) giving positive membrane immunofluorescent staining or cytoplasmic staining or both showed this to be due predominantly to IgG, but two (Cases 13 and 19) also showed IgA activity; in another (Case 10) IgA appeared to predominate. No IgM antibody was detected.

\section{Discussion}

The results show that specific antitumour activity is common in patients with carcinoma of the colon. We estimate the true incidence of the phenomenon to be near $50 \%$. This assessment is based on the incidence of lymphocytic or serum reactivity against tumour cell surface, which has more evident biological significance and has been entirely tumour-specific. Cytoplasmic immunofluorescence, which showed cross-reactivity in one serum (Case 19) against normal homologous colon mucosal cells, may well be only an epiphenomenon of tumour destruction in vivo (Nairn et al., 1971) and has been ignored in this calculation. One or more immunological reactions against tumour cell membrane occurred in 13 of the 60 cases studied, but only 21 were tested for all three membrane-reactive responses, 24 for lymphocytotoxicity, and 37 for serum cytotoxicity plus immunofluorescence. The figures almost certainly give a low estimate of overall immunoreactivity by the patients against their tumours because apart from unavoidable incomplete testing in the series various aspects of our test system favoured false-negative rather than false-positive results. In particular, a small lymphocyte to tumour cell ratio was employed in cytotoxicity tests and the extra antibiotics to prevent overgrowth of bowel organisms in culture could conceivably have restricted lymphocyte responsiveness; only unequivocal serum tests were reported positive.

Any lymphocytotoxicity was specific for colonic carcinoma, and cross-reactions between subjects were weaker than the autologous response. There was no cross-reactivity with other carcinomas or with normal colon whether homologous or autologous. Direct serum testing and absorption studies of complement-dependent cytotoxicity and membrane immunofluorescence also showed exclusive colonic carcinoma reactivity plus an irregular degree of individual specificity. Cytoplasmic immunofluorescence was restricted to colonic carcinomas except in Case 19, which also showed cross-reaction with homologous normal colon. Thus it seems established that the immunoreactivity is limited almost completely to colonic carcinoma while also having an individually specific component.

Lymphocytotoxicity was remarkably consistent in its crossreactions, and in repeat tests in Case 1 three different blood lymphocyte samples over a year showed no variation in activity. In contrast repeat sera sometimes showed reversal of the earlier response whether positive or negative-an original negative becoming positive may perhaps be explained by some form of antibody "release" after operative resection of antigenic tumour mass; the reverse process is presumably the more usual antibody subsidence after extirpation of antigenic stimulus and deserves further study as a possible favourable postoperative finding. The inconsistent cross-reactivity by sera in immunofluorescence tests with homologous colonic carcinomas is hard to explain. Possible fickle results in a delicate technical procedure could be responsible for only occasional anomalies and we are driven to conclude that the antibodies detected are directed against multiple antigens. No doubt a proportion of these are tumour-specific but some are probably shared with non-colonic carcinoma tissues. Presumably the carcinoma cells express different antigenicities from time to time and the antibody response will be correspondingly variable and not necessarily reactive against any current tumour cell population. Thus an antibody provoked by a tumour antigen eventually lost from the host may react against homologous but not autologous tumour.

As in the case of local lymphocyte reactivity in squamous cell carcinoma of the skin (Nairn et al., 1971) lymphocytes from the tumour itself present in the original cell suspension appeared to show no cytotoxic effect. Moreover, lymphocytes obtained from regional lymph nodes removed with four of the operation specimens, when added to the tumour cells in culture, gave negative cytotoxic results, even when, as in Case 4 , the blood lymphocyte response was shown to be positive. The suggestion already put forward that we are witnessing some form of local lymphocytic unresponsiveness seems equally cogent here. Two important biological questions now arise-is this phenomenon general and is it reversible? The studies required to answer these should be well worth while.

The relation of the present immunological reactivity against colonic carcinomas to carcinoembryonic antigen expression by these tumours has not yet been explored. It is quite possible that the response to common antigens of the carcinomas is directed against fetal intestinal antigens (Gold and Freedman, 1965; Martin and Martin, 1970), but the specific individual tumour antigenicity observed must be of a different nature. It could be a new tumour-specific antigen or even a re-emergent individual fetal antigen and we cannot see any practical way of distinguishing between these hypothetical possibilities in man.

Any clinical significance of our findings remains to be worked out. The persistence in patients' sera after operation of a positive cytoplasmic immunofluorescence response by itself has seemed to be a bad prognostic sign indicating incomplete removal of the tumour. Testing sera in this way could perhaps prove useful diagnostically. Lymphocytotoxicity is presumably the response of greatest significance for tumour rejection, and cell membrane-reactive serum antibodies may play some part in limiting humoral spread of malignant cells. We, however, have had no indication from the present study that either reactivity gives a specially favourable early postoperative course compared with immunonegative patients. It is doubtful that possible blocking of lymphocytotoxicity by cell-surface reactive noncytoclastic antibodies could have had any practical effect in vivo: pre-existing immunoglobulin binding to tumour cells was not observed in any of the present cases. The many factors concerned in postoperative survival demand the analysis of a greatly extended series of patients over at least a five-year period to permit assessment of any effect of immunopositive responsiveness on ultimate prognosis. We should also like to study further any possible association of more general immunological hypersensitivity in the immunopositive patients as suggested by the two cases of asthma and rheumatoid arthritis.

Active specific immunotherapy for colonic carcinoma cannot be contemplated with crude vaccines of autologous material from so contaminated a site and it may be fortunate that the tumour stimulates partial cross-reactivity with homologous colonic carcinomas. Highly purified carcinoembryonic antigens may be effective in this regard, perhaps most usefully to stimulate artificially cultivated autologous lymphocytes for therapeutic reinjection into the patient after optimum radical extirpation of tumour mass by conventional methods.

This work was supported by a grant from the Anti-Cancer Council of Victoria. For sending us specimens we thank Professor H. A. F. Dudley, Mr. J. S. Guest, Mr. N. T. Hamilton, and Dr. A. V. Jackson, of Alfred Hospital; Dr. J. F. Funder and Miss C. Beck, of Prince Henry's Hospital; and Mr. A. M. Cuthbertson, of the Royal Melbourne Hospital. We also thank Mrs. J. McNaughtan, Mrs. B. Lim, and Mr. D. Quinn for technical assistance, and Mr. R. Croker for the photomicrographic prints.

\section{References}

Gold, P. (1967). Cancer, 20, 1663.

Gold, P., and Freedman, S. O. (1965). Fournal of Experimental Medicine,

122, 467. fournal of Cancer, $6,346$.

Martin, F., and Martin, M. S. (1970). International fournal of Cancer, 6, 352. Nairn, R. C., Fothergill, J. E., McEntegart, M. G., and Richmond, H. G. (1962). British Medicai fournal, 1, 1791.

Nairn, R. C., Nind, A. P. P., Guli, E. P. G., Muller, H. K., Rolland, J. M., and Minty, C. C. J. (1971). British Medical fournal, 4, 701. 


\section{R. C. NAIRN ET AL.: IMMUNOLOGICAL REACTIVITY IN PATIENTS WITH CARCINOMA OF COLON}

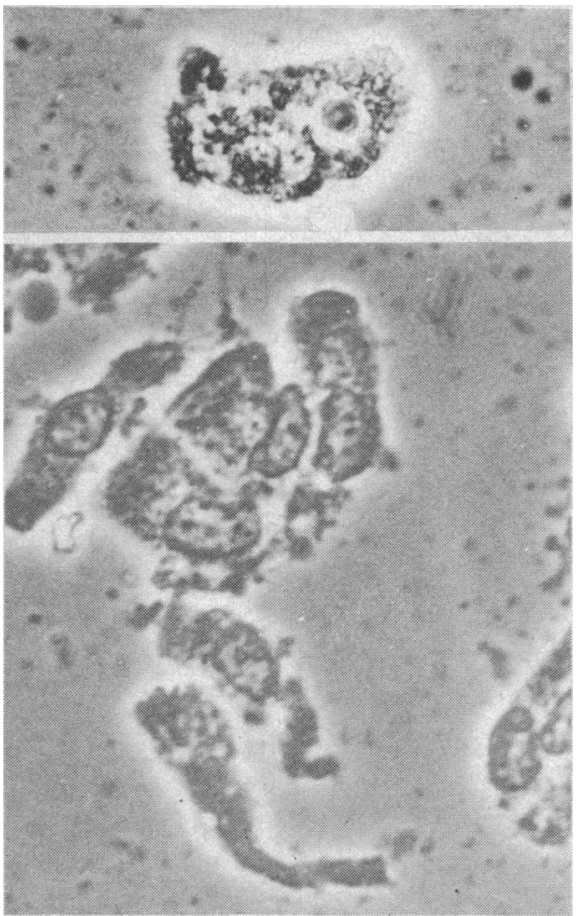

FIG. 1

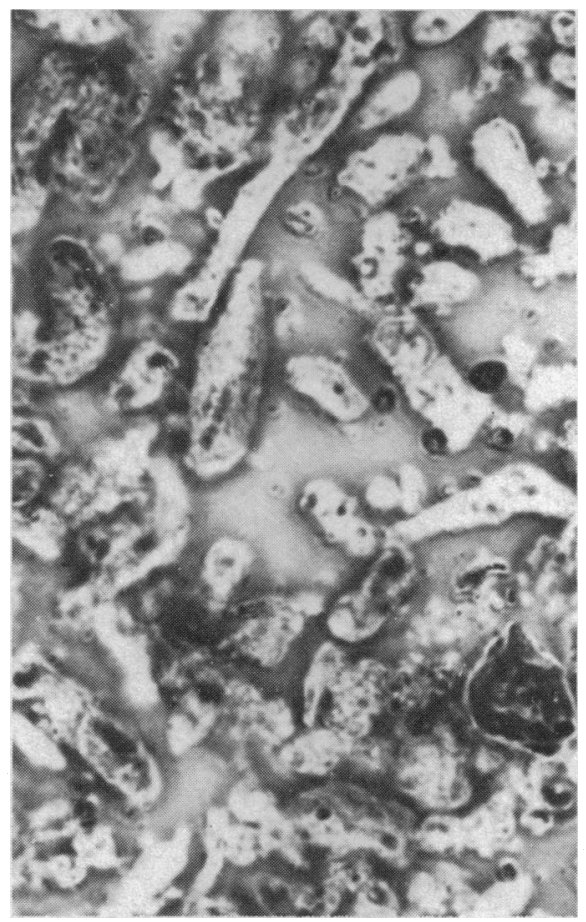

FIG. 2

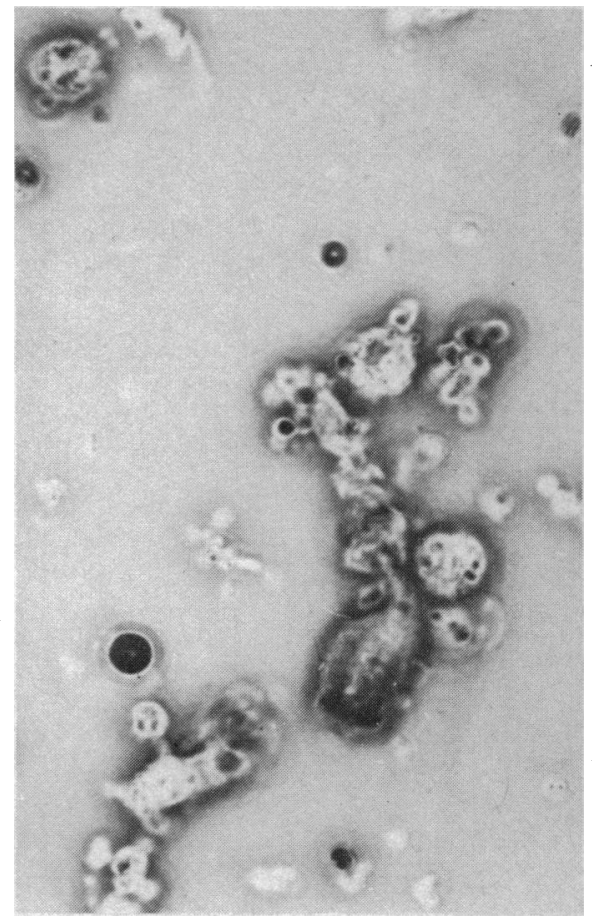

FIG. 3

FIGS. 1-3-Phase-contrast photomicrography. ( $\times$ 840.) FIG. 1-Colonic carcinoma cells in initial cell suspension. Above: Single cell from Case 13-note villiform appearance of luminal border to left. Below: Collection of granular columnar carcinoma cells from Case 1. FIG. 2-Cultured 5-day monolayer of colonic carcinoma cells from Case 1. FIG. 3-Same case as Fig. 2, showing parallel culture destroyed by autologous blood lymphocytes. Note degenerate carcinoma cells and remnants with attached lymphocytes.

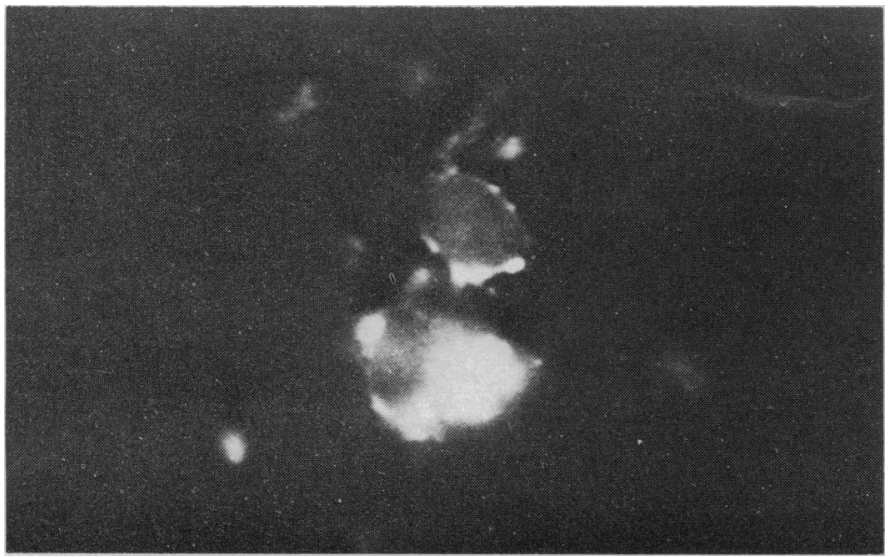

FIG. 4-Membrane immunofluorescence of viable cells in suspension from Case 9. Note speckled surface staining with, in upper cell, aggregation at lower margin probably corresponding to luminal border. Diffuse staining of dead cell lower right.



FIG. 6-Case 9. Cytoplasmic immunofluorescence of dried cell film. Note bipolar localization.

FIGS. 4-7-Immunofluorescence photomicrographs. ( $\times$ 900.)

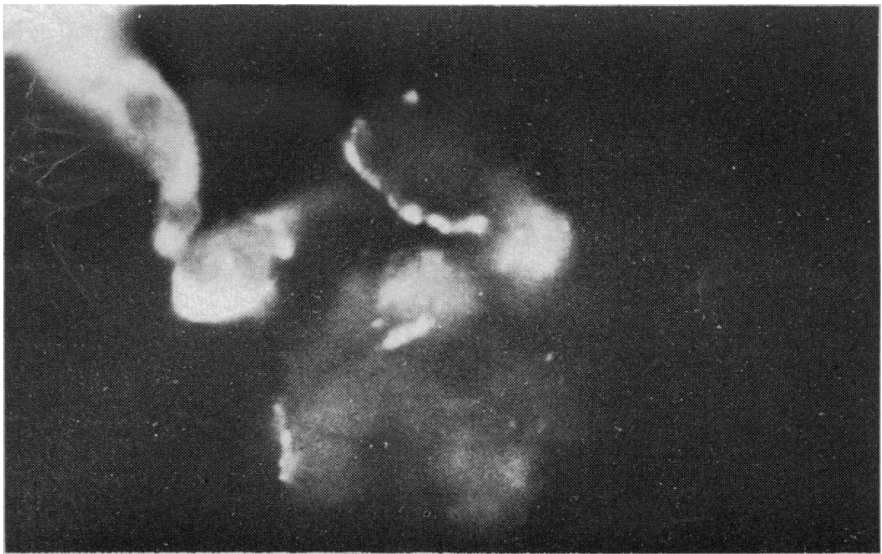

FIG. 5-Case 13. Membrane immunofluorescence. Speckled surface staining of viable cells in centre, and cytoplasmic staining of dead cells upper left.

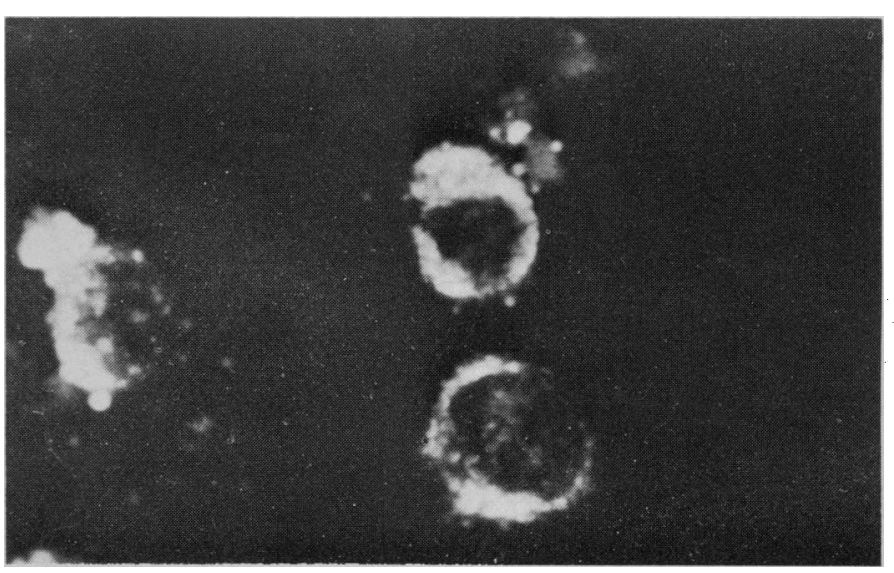

FIG. 7-Granular mitochondrial staining produced by autoantibody to mitochondria. To be distinguished from antitumour activity. Case 28, which showed no specific reactivity to colonic carcinoma. 